\title{
Italian biomedical research under fire
}

\author{
A short-sighted bill introduced in the Italian parliament could cripple scientific research in that country. Scientists \\ share some of the responsibility for this crisis.
}

西

t has been a tough couple of years for Italian scientists. It began with an announcement in July 2012 that funding at some national research institutes would be cut by $3.8 \%$ in 2012 and by a further $10 \%$ in 2013 and 2014. It got worse when, in October of 2012, a judge in the city of L'Aquila convicted six geoscientists and one government official of manslaughter, sentencing them each to 6 years in jail after they downplayed the risks of a recent tremor activity, days before a magnitude 6.3 earthquake hit the region. And now comes what may be the worst challenge for Italian science yet: in August of this year, the Italian parliament voted in favor of new legislation that, if enacted, is primed to completely undermine nearly all biomedical research in the country. Although this statute may not actually become law, at least in its current form, the very fact that this issue has cleared the first legislative hurdle indicates a deep conceptual disconnect between scientists and the Italian government; one that may stem, in part, from insufficient communication between researchers, lawmakers and the general public.

The story of this legislation begins with a European Union directive (Directive 2010/63/EU), adopted in September of 2010, that aimed to institute minimum standards in the usage of animals for scientific or educational endeavors. Although the directive mandated that all member states present their national animal care provisions by January 1, 2013, Italy is one of six EU nations that has so far failed to satisfy the directive. However, a bill that was recently approved by the Italian parliament goes far beyond the regulations outlined in the EU directive. This legislation, if approved by the Senate and enacted, would prohibit the breeding or use of cats, dogs and nonhuman primates for experiments, with the exception of clearly defined translational (human health-related) research purposes. In addition, the statute mandates that anesthesia or analgesic agents must be applied during any procedure in which the animal may experience some pain, except in cases where anesthesia or analgesia are the subject of the study. But, most worrisome of all is the directive that prohibits the use of all animals for xenotransplantations and in research programs aimed at the study of drugs of abuse.

It is not difficult to see how these restrictions, if implemented, could have catastrophic consequences for the entire Italian biomedical research community. If laboratories are unable to breed research animals, scientists will be forced to either abandon current research projects or acquire animals from lab animal distributors based outside of Italy, making most experiments prohibitively expensive. Furthermore, in addition to the elimination of primate, cat and dog model systems, the legislation also includes a vague provision that notes that the generation of genetically modified animals such as rodents will need to take into account the "potential risks to human health, animal welfare and the environment" (Article 13, LEGGE 6 agosto 2013, n. 96).
One could certainly imagine this rather ambiguous stipulation being interpreted in the harshest terms possible, perhaps even restricting the production and/or use of transgenic animals in Italy. Finally, this legislation would virtually end all possibility for research into the causes and treatment of drug addiction as well as those aimed at investigating the potential of stem cell replacement therapies, forcing laboratories currently working on these essential public health and well-being issues to either alter their research focus or move their labs to another country. These draconian measures, if ratified, will also compromise the ability of Italian researchers to compete for international funding. Forced to eliminate in vivo protocols, Italian scientists may find it difficult-if not impossible-to win highly competitive EU and international grants, leading to a 'snowball effect' in which shrinking budgets lead to a mass exodus of researchers out of Italy - a situation that will be disastrous for Italian biomedical science.

However, this crisis may still be averted. Although this legislation has been passed by the Italian parliament, it has yet to be ratified by the Italian Senate, and there is still a chance for the government to modify these regulations before they become law. And, in this context, it is important to note that the original EU Directive states that if any individual EU nation wishes to institute regulations stricter than those espoused therein, they must have been implemented prior to 2010 . Thus, it is possible that the Italian government may be forced to tone down the legislation in order to meet the Directive's requirements.

However, even if the legislation gets modified before ratification, it is important to ask how such a short-sighted and ill-advised bill could get passed in the Italian parliament in the first place. There is a feeling among many Italian scientists that the answer to this question appears to be a lack of basic scientific understanding among the general public. And although a persistent weakening of the quality of scientific education in Italy is partly to blame (and surely Italy is not alone in this predicament), it is important to recognize that scientists themselves bear some responsibility as well. Despite the increasing number of press offices at research institutes that excel at illustrating the simplified and practical implications of research studies, the scientific community has traditionally failed to adequately communicate the means by which biomedical research is carried out, leading to widespread misconceptions and mistrust by the population. Similarly, too few lawmakers actually understand how basic and translational research works and fail to seek the counsel of the scientists before considering legislation that could completely alter the research landscape in their country. Thus, it is essential for both the current Italian government and the scientific establishment to collaborate on improving scientific education and communication in the country. Only through a clear understanding by the public of the value and importance of animal research can such crises be avoided in the future. 